\title{
Histological and Morphological Study of the Intestines of Wistar Rat Fetuses in a Modified Gastroschisis Experimental Model
}

\author{
André Luis Hecht Sartori' ${ }^{1}$, Marina Ferreira Rosa de Vilhena ${ }^{1}$, Gabriela Samaha França², \\ Willy Marcus França ${ }^{3 *}$ \\ ${ }^{1}$ Faculty of Medical Science and Health, Catholic University of São Paulo (FCMS, PUC/SP), São Paulo, Brazil \\ ${ }^{2}$ São Paulo City University, São Paulo, Brazil \\ ${ }^{3}$ Pediatric Surgeon, Laboratory of Surgery Technique and Experimental Surgery, FCMS, PUC/SP, São Paulo, \\ Brazil \\ Email: willy@drwilly.com.br
}

Received 3 November 2015; accepted 22 February 2016; published 25 February 2016

Copyright @ 2016 by authors and Scientific Research Publishing Inc.

This work is licensed under the Creative Commons Attribution International License (CC BY).

http://creativecommons.org/licenses/by/4.0/

c) (i) Open Access

\begin{abstract}
In gastroschisis (G), the lesion degree of exposed intestinal segments is related to the time of its contact with the amniotic fluid (AF) and exposure to meconium which is the cause of intestinal morphological and histological alterations. The outcome of these alterations is intestinal hypoperistalsis and nutrient absorption deficiency, which contribute to increased morbidity and high medical-hospital costs. In this study, morphological and histological intestine alterations were identified at two different contact occasions with AF. Experimental gastroschisis (G) was performed on Wistar rat fetuses at a single gestational age on day $18.5^{\text {th }}$. The fetuses were removed on the 20.5 ${ }^{\text {th }}$ (G-1) and $21.5^{\text {th }}$ days (G-2). Fetuses of both groups were divided in 3 subgroups: control (C), gastroschisis (G) and sham (S). Measurements were taken of the Whole Set including fetus, placenta and membranes with AF (WS), fetus body weight (BW), intestinal weight (IW) and their diameters (DI). The objective of the present study is to test a new gastroschisis experimental model and identify differences in morphological and histological alterations in these two gestational periods that may be directly related to intestinal motility disorders in G. The WS and BW presented no significant statistical difference when compared G1 and G2. The results of the intestine average weight of G2 fetuses were significantly higher when compared to G1 fetuses in all subgroups (C: $p=$ 0.02; G: $p=0.01$; $: p=0.02$, Mann Whitney). The results of the intestinal average diameters (D/d) in G1 and G2 presented significant statistical difference only in G subgroup ( $p<0.05$, Kruskal Wallis). When compared intestinal average diameters, there was significant statistical difference of $G$ fetuses in G1 and G2 ( $p<0.05$, Mann Whitney). In conclusion, the present experimental G model was ade-
\end{abstract}

*Corresponding author.

How to cite this paper: Sartori, A.L.H., de Vilhena, M.F.R., França, G.S. and França, W.M. (2016) Histological and Morphological Study of the Intestines of Wistar Rat Fetuses in a Modified Gastroschisis Experimental Model. Surgical Science, 7, 72-81. http://dx.doi.org/10.4236/ss.2016.72010 
quate to reproduce $G$ in rat fetuses. All $G$ fetuses presented significant statistical difference when compared to other group in their subgroup and when compared G1 and G2 $(p<0.05)$. These alterations can explain the difficulties in accomplishing adequate peristalsis in $\mathrm{G}$ neonate bearers.

\title{
Keywords
}

\author{
Gastroschisis, Intestinal Damage, Intestinal Motility, Early Delivery
}

\section{Introduction}

Gastroschisis (G) is a congenital defect of the abdominal wall characterized by a small orifice usually located on the right side of the navel. The orifice allows herniation and permanent exposure of the intestinal sections to the amniotic fluid (AF) and its components up to the end of gestation [1] [2].

Despite the unknown etiology of the formation mechanism of abdominal congenital paraumbilical defect in gastroschisis, in 1981 some authors as Hoyme et al. [3]-[5] suggested that this defect would occur by regression or early lesion of one of the omphalo-mesenteric arteries in the embryonic phase in which the arteries binded the vitelline sac to the dorsal aorta [6]. Other vascular malformations such as involution of the right umbilical vein; interruption of the terminal branch of the superior mesenteric artery and/or rupture of the intra-uterus umbilical cord are also referred as causes of gastroschisis. Genetic alterations (family groups with autosomal inheritance pattern with variable expression), teratogenic alterations (radiation at the implantation phase) and drugs as acetylsalicylic acid, pseudoephedrine, acetaminophen and the use of tobacco will also be involved in its etiology [7] [8].

Permanent exposure of the intestinal sections to AF and its components causes alterations in their morphology and histology which results in intestinal hypomotility and nutrient absorption deficiency [9]-[11]. Hypomotility and intestinal absorptive deficiency in turn demand the utilization of prolonged parenteral nutrition and increase chances of postoperative complications, escalating morbidity and costs of medical hospital treatment [12] [13].

Literature on gastroschisis experimental models in female rats describes histological and morphological changes of intestinal sections exposed to AF and their consequent issues on peristalsis and nutrient absorption [14].

Given that the difference of intestinal sections exposure time to AF, different degrees of morpho-functional alterations in these sections may occur. Therefore, Hematoxylin-Eosin (HE) method is chosen to analyze these alterations, as well as the intestinal layers of the fetuses affected by experimental G [14].

The objective of the present study is to test a new G experimental model and to identify differences in morphological and histological alterations in these two gestational periods that may be directly related to intestinal motility disorders in G.

\section{Material and Method}

The current project was approved for the Ethical and Animal Experimentation Committee of FCMS, PUC—SP, campus Sorocaba.

Female Wistar rats, mean weight of 250 to $300 \mathrm{~g}$, were mated with male rats of the same species during nighttime. In the following morning, female genitalia were examined in order to verify the presence of sperm. The presence of sperm stain confirmed that the female rats had mated, and this day was considered gestation day zero [15]-[17].

Experimental $G$ was performed in a single gestation day: $18.5^{\text {th }}$ day 14 in fetuses from female Wistar rats (Diagram 1). The fetuses were divided in 2 groups according harvest in 2 different days of gestation: on the $20.5^{\text {th }}$ day (G1) composed by 16 fetuses and $21.5^{\text {th }}$ day (G2) composed by 16 fetuses (Diagram 2). Fetal body weights (BW) and intestinal weights (IW) were calculated. Hematoxylin-Eosin (HE) technique was used to examine the layers of the intestine walls.

After acclimation at the laboratory, the pregnant female Wistar rats were submitted to general anesthesia with ketamine base $-50 \mathrm{mg} / \mathrm{kg} / \mathrm{ml}$ (Ketamina ${ }^{\circledR}$-Pfizzer of Brasil) associated to xylazine $10 \mathrm{mg} / \mathrm{ml}$ (Rompum ${ }^{\circledR}$-Bayer 


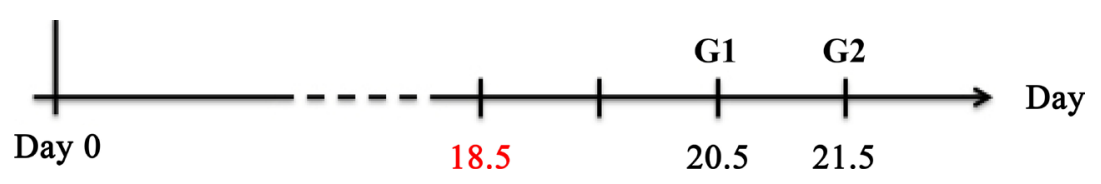

Diagram 1. Study design showing that sperm stain confirmed female rats mated, and this day was considered gestation Day Zero. Experimental $G$ was performed on the $18.5^{\text {th }}$ day and harvest of $\mathbf{G 1}$ was done on the $20.5^{\text {th }}$ day and $\mathbf{G} 2$ on the $21.5^{\text {th }}$ day.

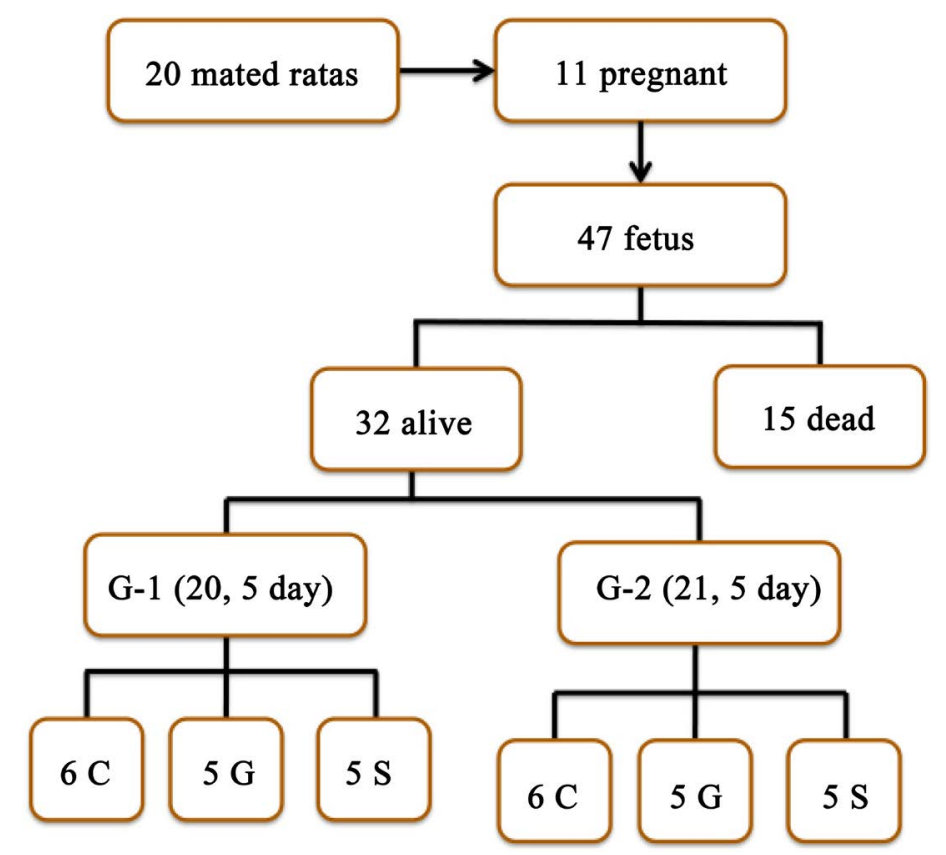

Diagram 2. Study design of fetal gatroschisis in female Wistar rats showing group subdivisions or subgroups: C-Control (6 fetus), G-Gastroschisis (5 fetus) and S-Sham (5 fetus) in each group.

of Brasil Ltda) at a dose of 0.4 - $0.5 \mathrm{ml}$ per animal injected in the thigh lateral musculature with an insulin syringe and a $20 \mathrm{G}$ needle. This anesthetic composition (180 mg/kg ketamine and $1.25 \mathrm{mg} / \mathrm{kg}$ xylazine) maintains the animal under deep anesthesia during a period of three hours, and postoperative period is painless during a period of 6 - 12 hour.

The female rats were submitted to exploratory laparotomy with open abdominal cavity and careful exteriorization of the bicorn uterus was carried out. Some fetuses were discarded due to their difference of size (number 1 and 7). Counting from the right uterine isthmus, the second fetus was placed in the control subgroup (C), followed by the fetus submitted to gastroschisis (G), and the subsequent fetus was positioned in the sham (S) subgroup. This sequence was successively repeated from the right corn to the left corn (Figure 1).

In order to perform gastroschisis, a stereoscopic optical microscope (lenses $\mathrm{Nitch}^{\circledR}-3.5 \mathrm{x}$ ) was used; a purse-string suture with Prolene ${ }^{\circledR} 6$ - 0 cord was made in the uterine wall [14] [18]. Subsequently, the uterus was opened in its two layers, muscular and amniotic membranes. The fetus was exposed by uterine incision up to the umbilical cord insertion and maintained with the superior abdomen and thorax in the interior of the maternal uterus. This technical maneuver decreases the risk of lesion of umbilical vessels and placenta during the gastroschisis procedure (Figure 2) [14] [19].

Accordingly, on the right side of umbilicus a very small hole was performed with a Halsted clip allowing intestinal loops being easily exposed to the amniotic fluid after a delicate compression on the fetal abdomen with sterilized cotton-tipped swabs. After the gastroschisis procedure, the fetus was carefully replaced in the uterine cavity and the uterus was closed by the purse-string suture previously prepared. Prior to closing the purse, $0.5 \mathrm{ml}$ of warm physiological solution was poured into the uterine cavity. During the procedure, the exposed portion of the fetus was maintained warm with saline solution $(\mathrm{NaCl} 0.9 \%)$ at $38^{\circ}$ Celsius trickled with a 5 ml syringe. The next fetus, denominated control fetus didn’t undergo surgery, nor was it removed from the uterus. The subse- 


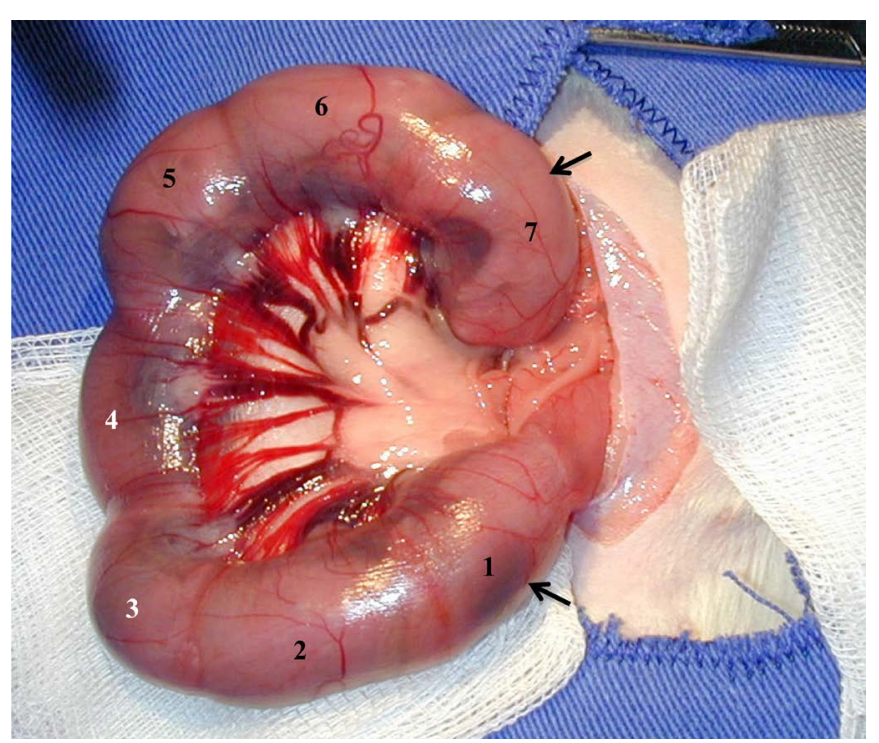

Figure 1. Photograph of right corn of female Wistar rats, showing fetuses numbered as $\mathbf{1}$ more proximal to the uterus and up to $\mathbf{7}$ more distal. The fetuses numberd from $\mathbf{2}$ to $\mathbf{6}$ were used in the study. Fetuses numbers $\mathbf{1}$ and 7, first and last, were excluded from the series.
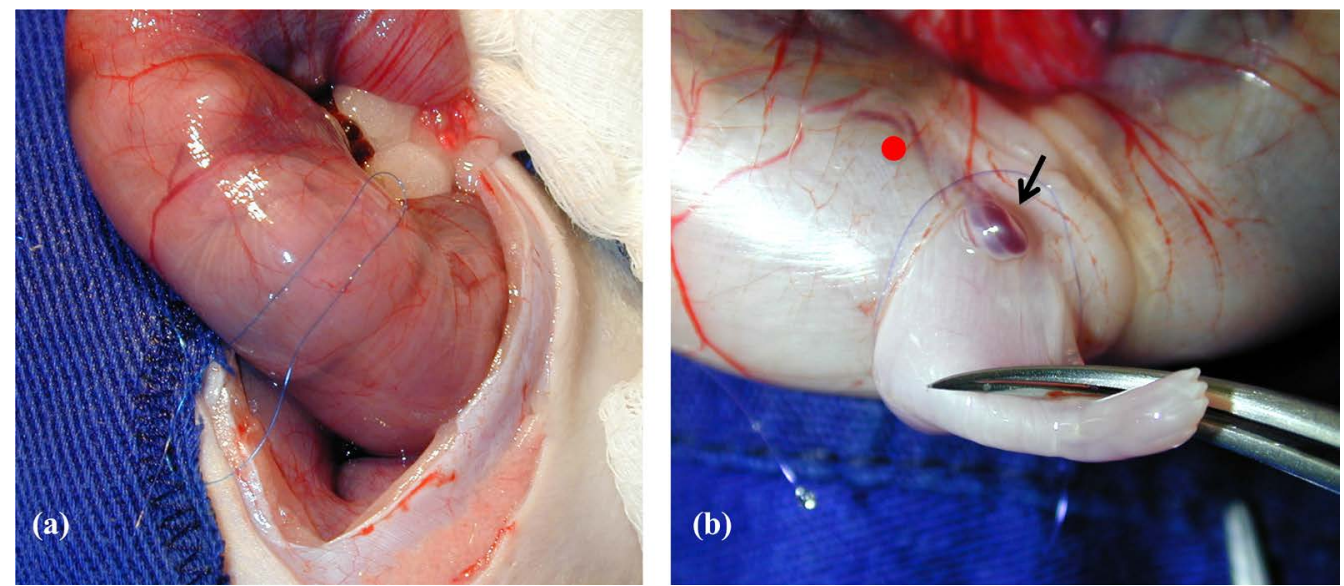

Figure 2. Photograph (a) shows a purse-string suture with Prolene ${ }^{\circledR} 6$ - 0 cord in the uterine wall. In (b) shows rigth leg of the fetus, umbilical cord (black arrow) and the place (red dot) that is going to be done the puncture in the abdominal wall that allows intestinal loops exteriorized as human gastroschisis.

quent fetus, denoted sham, was exposed outside the uterine cavity up to the height of the umbilical cord insertion. Then, it was submitted to a gentle compression on the right flank with cotton-tipped swabs. It did not undergo any surgical procedure, and it was put back in the uterine cavity.

At the end of the procedure performed on the existing fetuses, the abdominal wall of the mother rat was closed in two planes with a 5 - 0 nylon cord in continuous suture. The female rats were maintained on inhaling oxygen through an adapted mask until they were fully awaken and moving with no difficulty. In the postoperative period, the rats were maintained in metallic cages with sawdust bedding in individual stalls. Water and diet were offered ad libitum.

G-1 and G-2 female rats were submitted again to Cesarean section through a median incision on day $20.5^{\text {th }}$ and $21.5^{\text {th }}$, respectively. In the next step, a small incision was made on the uterine wall with a microsurgical scissors, delicately dislocating the gestational sac with a swab. Care was taken to avoid the gestational sac rupture. The gestational sac containing the fetus, placenta, membranes and AF were removed intact from the uterus and it was called whole set of fetuses. A precision balance model Marte AS $2000^{\circledR}$ was used to weigh all fetuses and their intestinal loops. After weighing, the gestational sac was ruptured and the fetus removed and weighed 
isolated and all intestinal loops for each group were weighed as well.

In other to compare all the results between subgroups $\mathbf{C}, \mathbf{G}$ and $\mathbf{S}$ in the same group but for both groups was used Kruskal-Wallis Test to verify significant statistical difference $(p<0.05)$. To study significant statistical difference between the groups (G1 $\times$ G2) was used Mann-Whitney Test for two independent groups $(p<0.05)$.

\section{Results}

In this study 20 female Wistar rats were mated, but only 11 became pregnant. A total of 47 fetuses were obtained; 32 fetuses were alive and healthy, however, 15 were discarded after intra-uterus death that it could not identified the cause. Sixteen of the 32 live fetuses were submitted to investigation on the $20.5^{\text {th }}$ day $(\mathbf{G}-\mathbf{1})$ and 16 others were submitted to investigation on the $21.5^{\text {st }}$ day (G-2). Fetuses of both groups were divided in 3 subgroups: control (C), gastroschisis (G) and sham (S). Measurements were taken of the Whole Set (WS), including fetus, placenta and membranes with AF, fetus body weight (BW), intestinal weight (IW) and their diameters (DI) (Figure 3).

In G-1 the average weight in grams (g) of whole set of fetuses (Figure 5) were: C: 4.16 g; G: 4.04 g; S: 4.21 $\mathrm{g}(p=0.52)$. It was also obtained the average weight of their bodies: C: $2.43 \mathrm{~g} ; \mathbf{G}: 2.34 \mathrm{~g} ; \mathbf{S}: 2.46 \mathrm{~g}(p=0.41)$. The average weight of the intestinal loops (Figure 6) was: C: $0.13 \mathrm{~g}$; G: $0.16 \mathrm{~g} ; \mathrm{S}: 0.11 \mathrm{~g}(p=0.01$ ). Significant statistical difference was obtained only when compared the average weight of the intestinal loops among the 3 subgroups in G-1 ( $p=0.01$, Kruskal Wallis) (Table 1$)$.

In G-2 the average weight in grams (g) of whole set of fetuses were: C: $4.23 \mathrm{~g} ; \mathbf{G}: 4.20 \mathrm{~g} ; \mathrm{S}: 4.24 \mathrm{~g}(p=0.90)$. It was also obtained the average weight of their bodies: C: $2.43 \mathrm{~g}$; G: $2.34 \mathrm{~g}(p=0.90)$; S: $2.46 \mathrm{~g}(p=0.95)$. The average weight of the intestinal loops (Figure 4) was: C: $0.13 \mathrm{~g}$; G: $0.16 \mathrm{~g}$; S: $0.11 \mathrm{~g}(p=0.55)$ (Table 2). There was no significant statistical difference when compared the WS, BW, IW and DI in this subgroup.

Comparing fetuses in the 2 groups, we can see that there was no significant statistical difference when compared the average weight of WS and BW among G1 and G2 between the 3 subgroups (C: $p=0.40 ; \mathbf{G}: p=0.10$; $\mathbf{S}: p=$ 0.23, Mann Whitney Test).

There was observed significant statistical difference when compared the average weight of intestinal loops in the 3 subgroups between the 2 groups (C: $p=0.01 ; \mathbf{G}: p=0.01 ; \mathbf{S}: p=0.01$, Mann Whitney Test).

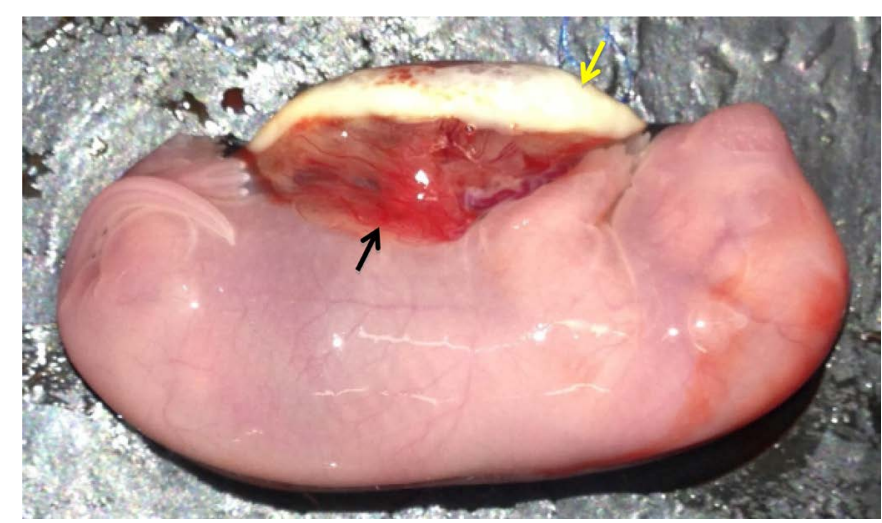

Figure 3. Full set showing fetus with amniotic membrane, placenta and AF. Yellow arrow shows Placenta and black arrow shows umbilical cord inside placenta.

Table 1. Shows the average weight in grams (g) of whole set of fetuses, the average weight of the fetuses bodies, the average weight of the intestinal loops and the average of intestinal diameters $(\boldsymbol{\mu m})$ in fetuses of $\mathbf{G}-\mathbf{1}$.

\begin{tabular}{cccc}
\hline G-1 Fetuses & Control & Gastroschisis & Sham \\
\hline Whole set weight & $4.16 \mathrm{~g}$ & $4.04 \mathrm{~g}$ & $4.21 \mathrm{~g}$ \\
Body weight & $2.43 \mathrm{~g}$ & $2.34 \mathrm{~g}$ & $2.46 \mathrm{~g}$ \\
Intestinal loop weight & $0.13 \mathrm{~g}$ & $0.16 \mathrm{~g}^{*}$ & $0.11 \mathrm{~g}$ \\
Intestinal Diameters (Dxd) & $561.06 \boldsymbol{\mu m}$ & $824.29 \boldsymbol{\mu m}$ & $622.05 \boldsymbol{\mu m}$ \\
\hline
\end{tabular}

OBS: *With significant statistical difference, $p<0.01$. 


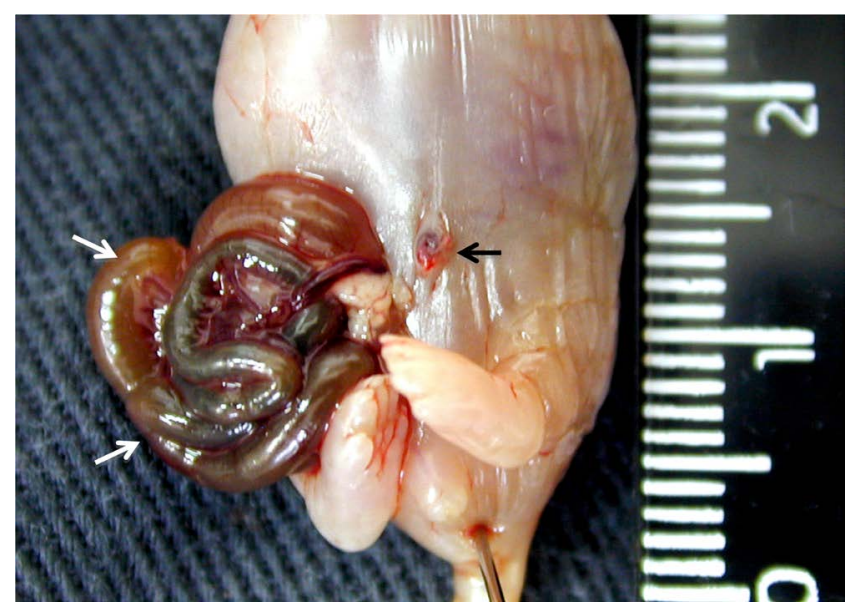

Figure 4. Intestines loops not removed yet from G-1 fetus to be weighed (white arrows). Black arrow shows umbilical site.

Table 2. Shows the average weight in grams (g) of whole set of fetuses, the average weight of their bodies, the average weight of the intestinal loops and the average of intestinal diameters in micrometer $(\mu \mathrm{m})$ in fetuses of G-2.

\begin{tabular}{cccc}
\hline G-2 Fetuses & Control & Gastroschisis & Sham \\
\hline Whole set weight & $4.23 \mathrm{~g}$ & $4.20 \mathrm{~g}$ & $4.24 \mathrm{~g}$ \\
Body weight & $2.64 \mathrm{~g}$ & $2.59 \mathrm{~g}$ & $2.61 \mathrm{~g}$ \\
Intestinal loop weight & $0.17 \mathrm{~g}^{*}$ & $0.20 \mathrm{~g}^{*}$ & $0.18 \mathrm{~g}^{*}$ \\
Intestinal Diameters $(\mathbf{D} \times \mathbf{d})$ & $665.40 \mu \mathrm{m}$ & $847.45 \mu \mathrm{m}$ & $737.86 \mu \mathrm{m}$ \\
\hline
\end{tabular}

OBS: *There was no significant statistical difference when compared the WS, BW, IW and DI in G-2.

When the avarege of the diameters ( $\mathbf{D}$ and $\mathbf{d}$ ), are compared among the 3 subgroups in $\mathbf{G}-\mathbf{1}$ there was a significant statistical difference when compared $\mathbf{C}$ with $\mathbf{G}(p<0.05$, Mann Whitney Test), but not when compared C with $\mathbf{S}$ and $\mathbf{G}$ with S. In the $\mathbf{G}-\mathbf{2}$ significant statistical difference was observed as well when compared $\mathbf{C}$ with $\mathbf{G}$ ( $p<$ 0.05, Mann Whitney Test), but not when compared $\mathbf{C}$ with $\mathbf{S}$ and $\mathbf{G}$ with $\mathbf{S}$.

When each subgroup was compared between both groups there was a significant statistical difference in all of them: C: $p=0.002 ; \mathbf{G}: p=0.05$ and $\mathbf{S}: p=0.004$ (Mann Whitney Test).

Seven fetuses were reabsorbed and were not added to the weighing results given that they had lost the typical anatomical characteristics (Figure 5 and Figure 6).

The measurement of the length of intestines was not performed due to their frailness, since they were too small and filmy.

The measurements in micrometers $(\mu \mathrm{m})$ were taken from diameters $\mathbf{D}$ (larger diameter, from mesenteric edge to anti-mesenteric edge) and $\mathbf{d}$ (smaller diameter, from lateral to lateral edges) of the intestines of fetuses $\mathbf{C}, \mathbf{S}$ and $\mathbf{G}$ (Figure 7).

The results obtained for G-1 D measurements average were: (Figure 8(a)) $\mathbf{C}=729.73, \mathbf{S}=847.60$ and $\mathbf{G}=$ $1096.56(\mathbf{C} \times \mathbf{G}, p<0.05$, DUNN Method). There was a significant statistical difference when compared into this sub-group ( $p=0.0013$, Kruskal Wallis). The measurement averages of $\mathbf{G}-\mathbf{1} \mathbf{d}$ were: $\mathbf{C}=392.93, \mathbf{S}=396.51$ and $\mathbf{G}=552.01(\mathbf{C} \times \mathbf{G}$ and $\mathbf{G} \times \mathbf{S}, p<0.05$, DUNN Method, both). There was a significant statistical difference when compared into this sub-group ( $p=0.0077$, Kruskal Wallis).

The mean average of $\mathbf{D}$ measurements for $\mathbf{G} 2$ results was: (Figure $8(\mathbf{b})$ ) $\mathbf{C}=738.24, \mathbf{S}=897.60$ and $\mathbf{G}=$ $1007.43(p<0.05$, DUNN Method). There was a significant statistical difference when compared into this sub-group ( $p=0.0013$, Kruskal Wallis). The measurement average of $\mathbf{d}$ was: $\mathbf{C}=547.56, \mathbf{S}=578.12$ and $\mathbf{G}=$ 687.38 ( $\mathbf{C} \times \mathbf{G}, p<0.05$, DUNN Method). There was a significant statistical difference when compared into this sub-group ( $p=0.0029$, Kruskal Wallis).

\section{Discussion}

Intestine anatomical and functional damages occur not only by direct contact with AF, but mainly by action of 


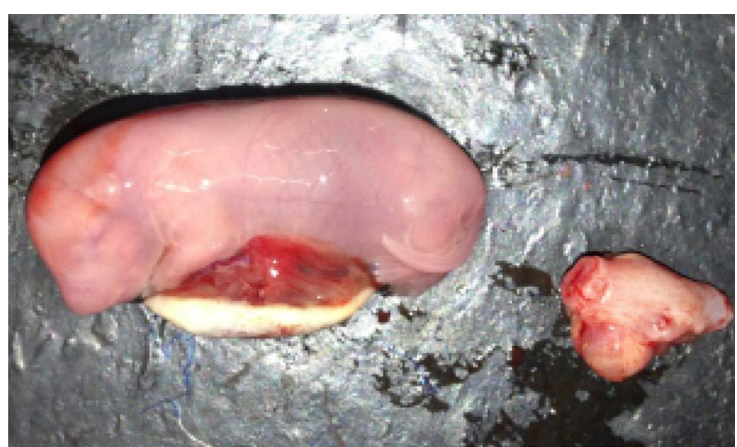

Figure 5. The image shows size differences between the normal fetus on the left (bigger) and the reabsorbed (smaller) fetus and placenta on the right.

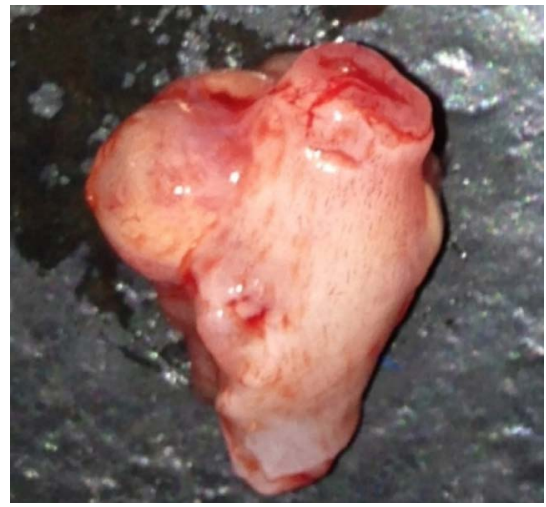

Figure 6. Image of a reabsorbed fetus.

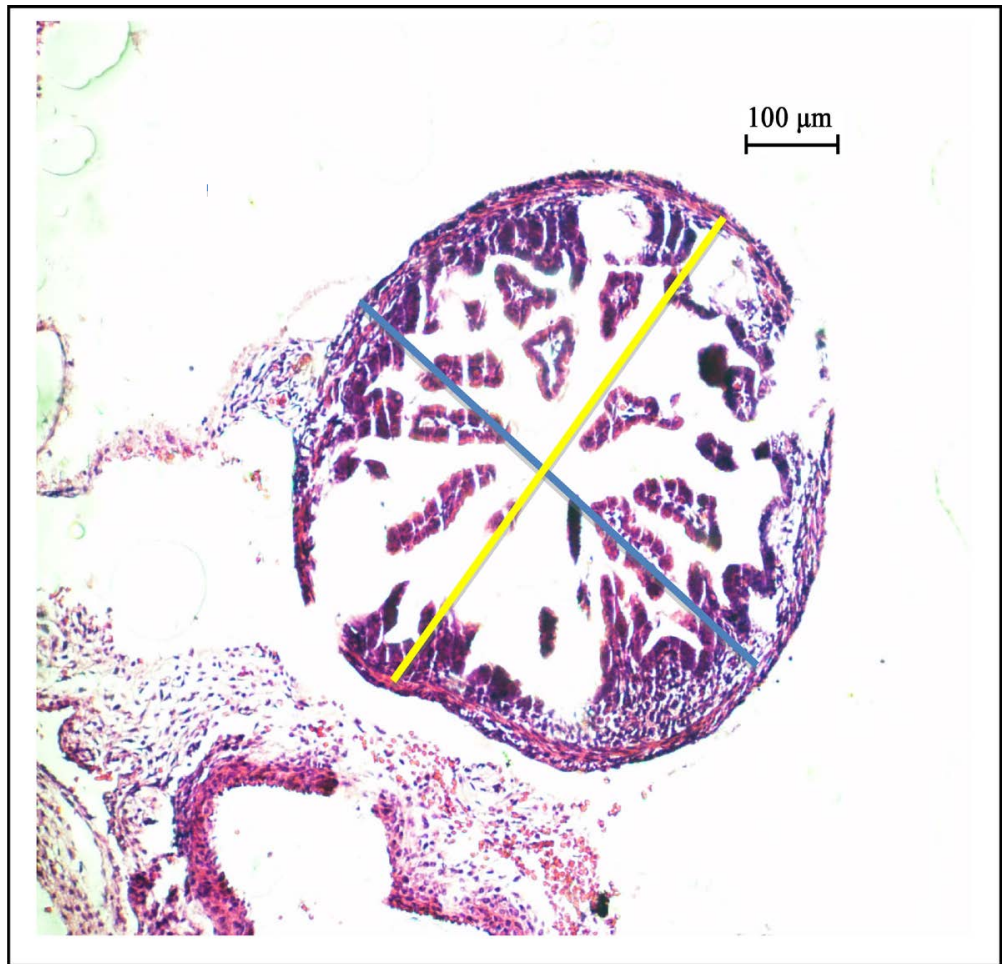

Figure 7. Photomicrograph of G-1 rat fetus intestine cross section. Drawing shows D (yellow, from mesenteric edge to anti-mesenteric edge) and $\mathbf{d}$ (blue, lateral to lateral edges) measurements (size 100x). 


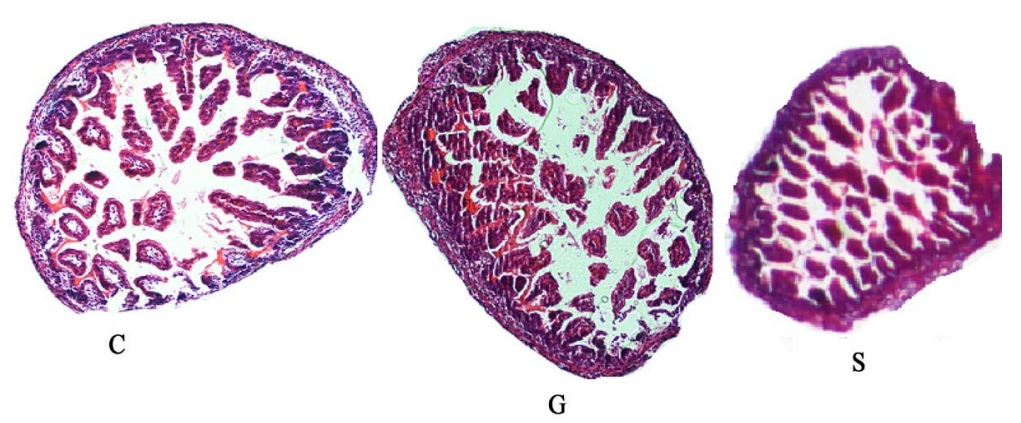

(a)

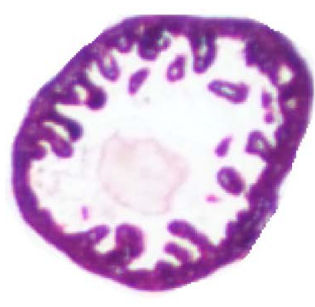

$\mathrm{C}$

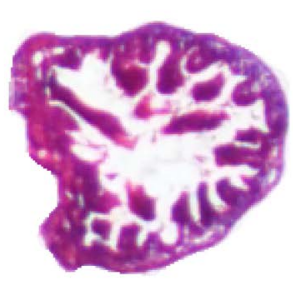

G

(b)

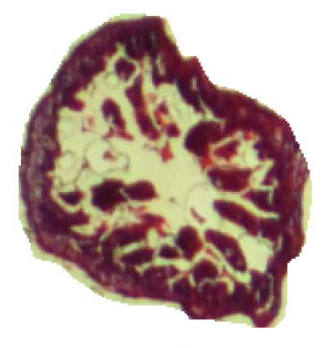

S

Figure 8. (a) Photomicrography (100x) of intestines of G-1 rats; (b) Photomicrography (100x) of intestines of G-2 rats.

fetus meconium excretion during gestation and time of exposure to AF that aggravates the lesion on the intestinal wall [20].

Damage to intestinal sections in $\mathbf{G}$ occurs more often at the end of gestation in human fetuses; and lesions become acute after the $30^{\text {th }}$ week of gestation with the formation of fibrous peel, which promotes progressive alterations in the intestinal serosa [21] [22]. Thus, delivery method and anticipation, despite the lack of consensus on the conduct regarding fetus affected by G, will be a way to avoid damage to the intestinal sections [23] [24]. Early delivery will bring positive outcomes given that primary correction is straightforward, mortality rates are low and hospitalization period is shorter. Furthermore, there will be fewer morphological and histological structural alterations of the intestine exposed to AF at the end of gestation [25] [26].

The most recurrent structural alterations found in intestinal G are: thickening of it walls, weight gain, short length and development of fibrous peel on serosa [27] [28].

As described in the literature, the results of the intestine average weights of the fetuses $\mathbf{G 1}$ and $\mathbf{G} \mathbf{2}$ are significantly higher when compared to their respective Controls and Shams groups $(p<0.05)$. The results of the intestine average weights of fetuses G2 are significantly higher when compared to fetuses G1 $(p<0.05)$, according to França WM et al., 200614. These alterations can explain the difficulties in accomplishing adequate peristalsis in $\mathbf{G}$ neonate bearers which result in all the complications previously described.

The results obtained in the present study show that IW in the subgroup $\mathbf{G}$ is greater ( $p<0.014$, Mann Whitney) when compared to their respective subgroups $\mathbf{C}(p<0.018)$ and $\mathbf{S}(p<0.018)$, probably influenced by the longer exposure time to AF in fetuses of $\mathbf{G 2}$ [21].

The latter also occurs with the averages of intestinal wall diameters in both groups (G1 and G2) when fetuses $\mathbf{G}$ are compared to their respective subgroups $\mathbf{C}$ and $\mathbf{S}(p<0.05)$. When $\mathbf{G} \mathbf{1}$ is compared to $\mathbf{G} \mathbf{2}$ with regard to diameter averages, it is observed that there are significant statistical differences when compared fetuses in the same sub-group, for both groups, $\mathbf{G} 1$ and $\mathbf{G} 2(p>0.05)$.

Therefore, the $\mathbf{G}$ experimental modified model proposed in the present study confirmed the results described in the literature with a significant difference between the two gestation days [14], which gave emphasis to morphological and histological alterations in the intestines of fetuses $\mathbf{G}$, confirming that it worsened with longer exposure time to $\mathrm{AF}[14]$.

\section{References}

[1] Skandalakis, J.E. and Gray, S.W. (1972) Embryology for Surgeons. The Embryological Basis for the Treatment of 
Congenital Anomalies. 2nd Edition, WB Saunders, Philadelphia, 414-415.

[2] Aoki, Y., Ohshio, T. and Komi, N. (1980) An Experimental Study on Gastroschisis Using Fetal Surgery. Journal of Pediatric Surgery, 15, 252-256. http://dx.doi.org/10.1016/S0022-3468(80)80131-X

[3] Saxena, A.K., et al. (2002) Gastroschisis: A 15-Year, Single-Center Experience. Pediatric Surgery International, 18, 420-424. http://dx.doi.org/10.1007/s00383-002-0799-y

[4] Singh, S.J., et al. (2003) Gastroschisis: Determinants of Neonatal Outcome. Pediatric Surgery International, 19, 260265. http://dx.doi.org/10.1007/s00383-002-0886-0

[5] Davis, M.W., Kimble, R.M. and Cartwrigth, D.W. (2005) Gastroschisis: Ward Reduction Compared with Tradiotional Reduction under General Anesthesia. Journal of Pediatric Surgery, 40, 523-527. http://dx.doi.org/10.1016/j.jpedsurg.2004.11.030

[6] Hoyme, E.W., Higginbottom, M.C. and Jones, K.L. (1981) The Vascular Pathogenesis of Gastroschisis: Intrauterine Interruption of the Omphalomesenteric Artery. Journal of Pediatrics, 98, 228-231. http://dx.doi.org/10.1016/S0022-3476(81)80640-3

[7] Wilson, D. and Johnson, M.P. (2004) Congenital Abdominal Wall Defects: An Update. Fetal Diagnosis and Therapy, 19, 385-398. http://dx.doi.org/10.1159/000078990

[8] Kunz, L.H.; Gilbert, W.M. and Towner, D.R. (2005) Increased Incidence of Cardiac Anomalies in Pregnancies Complicated by Gastroschisis. American Journal of Obstetrics \& Gynecology, 193, 1248-1252. http://dx.doi.org/10.1016/j.ajog.2005.05.080

[9] Srinathan, S.K., et al. (1995) Etiology of Intestinal Damage in Gastroschisis. III: Morphometric Analysis of the Smooth Muscle and Submucosa. Journal of Pediatric Surgery, 30, 379-383. http://dx.doi.org/10.1016/0022-3468(95)90036-5

[10] Dilsiz, A., et al. (1999) Nitric Oxide Synthase Inhibition Prevents Intestinal Damage in Gastroschisis: A Morphological Evaluation in Chick Embryos. Journal of Pediatric Surgery, 34, 1248-1252. http://dx.doi.org/10.1016/S0022-3468(99)90161-6

[11] Santos, M.M., Tannuri, U. and Maksoud, J.G. (2003) Alterations of Enteric Nerve Plexus in Experimental Gastroschisis: Is There a Delay in the Maturation? Journal of Pediatric Surgery, 38, 1506-1511. http://dx.doi.org/10.1016/S0022-3468(03)00504-9

[12] Morrison, J.J., Klein, N., Chitty, L.S., et al. (1998) Intra-Amniotic Inflammation in Human Gastroschisis: Possible Aetiology of Postnatal Bowel Dysfunction. British Journal of Obstetrics and Gynaecology, 105, 1200-1204. http://dx.doi.org/10.1111/j.1471-0528.1998.tb09975.x

[13] Sydorak, R.M., Nijagal, A., Sbragia, L., et al. (2002) A Big Hole in the System: Gastroschisis. Journal of Pediatric Surgery, 37, 1669-1672. http://dx.doi.org/10.1053/jpsu.2002.36689

[14] França, W.M., Langone, F., de la Hoz, C.L.R., et al. (2006) Maturity of the Myenteric Plexus Is Decreased in the Gastroschisis Rat Model. Fetal Diagnosis and Therapy, 23, 60-68. http://dx.doi.org/10.1159/000109228

[15] Qi, B.Q., Diez-Pardo, J.A., Navarro, C. and Tovar, J.A. (1996) Narrowing the Embryologic Window of the Adriamycin-Induced Rat Model of Esophageal Atresia and Tracheoesophageal Fistula. Pediatric Surgery International, 11, 444-447. http://dx.doi.org/10.1007/BF00180079

[16] Crisera, C.A., Rose, M.I., et al. (1999) The Ontogeny of TGF- $\beta 1,-\beta 2$, $-\beta 3$, and TGF- $\beta$ Receptor-II Expression in the Pancreas: Implications for Regulation of Growth and Differentiation. Journal of Pediatric Surgery, 34, 774-779. http://dx.doi.org/10.1016/S0022-3468(99)90357-3

[17] Correia-Pinto, J., Tavares, M.L., Baptista, M.J., et al. (2001) A New Fetal Rat Model of Gastroschisis: Development and Early Characterization. Journal of Pediatric Surgery, 36, 213-216. http://dx.doi.org/10.1053/jpsu.2001.20057

[18] Gonçalves, F.L., de Souza, G.F., Schmidt, A.F., et al. (2011) Evaluation of Nitric Oxide (NO) and Nitric Oxide Synthases (NOS) in the Amniotic Fluid in an Experimental Gastroschisis Rat Model. European Journal of Pediatric Surgery, 21, 362-365.

[19] Guo, W., Swaniker, F., Fonkalsrud, E.W., et al. (1995) Effect of Intraamniotic Dexamethasone Administration on Intestinal Absorption in a Rabbit Gastroschisis Model. Journal of Pediatric Surgery, 30, 983-986; Discussion 986-987. http://dx.doi.org/10.1016/0022-3468(95)90326-7

[20] Langer, J.C., Longaker, M.T., Crombleholme, T.M., et al. (1989) Etiology of Intestinal Damage in Gastroschisis. I.-Effects of Amniotic Fluid Exposure and Bowel Constriction in a Fetal Lamb Model. Journal of Pediatric Surgery, 24, 992-997. http://dx.doi.org/10.1016/S0022-3468(89)80200-3

[21] Langer, J.C., Bell, J.G., Castillo, R.O., et al. (1990) Etiology of Intestinal Damage in Gastroschisis, II. Timing and Reversibility of Histological Changes, Mucosal Function, and Contractility. Journal of Pediatric Surgery, 25, 1122-1126. http://dx.doi.org/10.1016/0022-3468(90)90745-U 
[22] Tibboel, D., Verney-Keers, C., Kluck, P., et al. (1986) The Natural History of Gastroschisis during Fetal Life: Development of the Fibrous Coating on the Bowel Loops. Teratology, 33, 267-272. http://dx.doi.org/10.1002/tera.1420330303

[23] Moore T.C., Collins, D.L., Catanzarite, V., et al. (1999) Pre-Term and Particularly Pre-Labor Cesarean Section to Avoid Complications of Gastroschisis. Pediatric Surgery International, 15, 97-104. http://dx.doi.org/10.1007/s003830050525

[24] Huang, J., Kurkchubasche, A.G., Carr, S.R., et al. (2002) Benefits of Term Delivery in Infants with Antenatally Diagnosed Gastroschisis. Obstetrics \& Gynecology, 100, 695-699. http://dx.doi.org/10.1016/S0029-7844(02)02170-1

[25] Fitzsimmons, J., Nyberg, D.A., Cyr, D.R. and Hastch, E. (1988) Perinatal Management of Gastroschisis. Obstetrics \& Gynecology, 71, 910-913.

[26] Dunn, J.C.Y., Fonkalsrud, E.W. and Atkinson, J.B. (1999) The Influence of Gestacional Age and Mode of Delivery on Infants with Gastroschisis. Journal of Pediatric Surgery, 34, 1393-1395. http://dx.doi.org/10.1016/S0022-3468(99)90017-9

[27] Deans, K.J., Mooney, D.P., Meyer, M.M. and Shorter, N.A. (1999) Prolonged Intestinal Exposure to Amniotic Fluid Does Not Result in Peel Formation in Gastroschisis. Journal of Pediatric Surgery, 34, 975-976. http://dx.doi.org/10.1016/S0022-3468(99)90771-6

[28] Correia-Pinto, J., Tavares, M.L., Baptista, M.J., et al. (2002) Meconium Dependence of Bowel Damage in Gastroschisis. Journal of Pediatric Surgery, 37, 31-35. http://dx.doi.org/10.1053/jpsu.2002.29422 